\title{
Abnormality of pituitary gonadal axis among Nigerian males with infertility: study of patterns and possible etiologic interrelationships
}

This article was published in the following Dove Press journal:

Open Access Journal of Urology

4 August 2011

Number of times this article has been viewed

\section{OFN Ozoemena' \\ JO Ezugworie ${ }^{2}$ \\ $\mathrm{AU} \mathrm{Mbah}^{3}$ \\ EA Esom ${ }^{4}$ \\ BO Ayogu ${ }^{5}$ \\ FE Ejezie ${ }^{6}$}

'Department of Anatomy and Surgery, ${ }^{2}$ Department of Obstetrics and Gynecology, ${ }^{3}$ Department of Pharmacology and Therapeutics, College of Medicine, University of Nigeria Teaching Hospital, ${ }^{4}$ Department of Anatomy, College of Medicine, University of Nigeria Enugu Campus; ${ }^{5}$ Urology Unit, Department of Surgery, University of Nigeria Teaching Hospital, Ituku/Ozalla; ${ }^{6}$ Department of Medical Biochemistry, College of Medicine, University of Nigeria, Enugu Campus,

Enugu, Nigeria
Correspondence: OFN Ozoemena Department of Anatomy and Surgery, College of Medicine, University of Nigeria Teaching Hospital, Ituku/Ozalla, Nigeria Tel +80334 I 9825

Email nneomakamsi@yahoo.com
Background: Hormonal derangements potentially contribute to the diagnosis of infertility in over $60 \%-70 \%$ of couples investigated. Use of hormonal and antihormonal agents has achieved great success in the treatment of male infertility. Our aim was to investigate the prevalence of hormonal abnormalities in males diagnosed with infertility.

Methods: Males diagnosed clinically with infertility and referred from the gynecologic clinics of the University of Nigeria Teaching Hospital, Ituku/Ozalla, Enugu State University Teaching Hospital, and some private hospitals in and around Enugu metropolis were recruited for the study. They were grouped according to whether they had primary or secondary infertility on the basis of the World Health Organization definition. Routine fertility test profiles for the subjects were evaluated, and detailed hormonal assays were analyzed.

Results: Of 216 men, $173(80.1 \%)$ were found to have a hormonal imbalance. The mean age was $47.7 \pm 3.5$ (range 30-55) years for primary infertility and $47.2 \pm 6.8$ (range 33-61) years for secondary infertility. Patterns of hormonal abnormalities diagnosed amongst the $62(35.80 \%)$ primary infertility subjects included hypergonadotrophic hypogonadism in 39 (62.90\%), hypogonadotrophic hypogonadism in 18 (29.03\%), and hyperprolactinemia in five (8.07\%). Among the 111 (64.2\%) cases of secondary infertility, there were 55 (49.55\%) cases of hypergonadotrophic hypogonadism, 52 (46.85\%) of hypogonadotrophic hypogonadism, and four $(3.60 \%)$ of hyperprolactinemia. There was no statistically significant difference in the mean values between the two groups $\left(\chi^{2}<1.414 ; P>0.05\right)$ for hormonal indices.

Conclusion: The hormonal profile should be considered as the gold standard for diagnosis and management of male infertility.

Keywords: infertility, hormonal indices, males

\section{Introduction}

Infertility can be defined as the inability of a couple to conceive after 12 months of contraceptive-free intercourse. ${ }^{1}$ Infertility remains a common medical problem in developing countries. ${ }^{2}$ Between $8 \%$ and $12 \%$ of couples around the globe have the problem of infertility. In developing countries, infertility has been associated with traditional beliefs and myths, such as witchcraft, punishment by the gods for acts of wickedness, or a curse. ${ }^{3}$

Various factors affecting either one or both partners are known to cause infertility. Ignorance about the timing of ovulation, ie, the female monthly cycle, is a major factor. Despite this knowledge, the woman is always on the receiving end, because she is blamed and held responsible for infertility. She is often accused of living an indecent life and, as such, may have destroyed her womb by promiscuity and abortions. ${ }^{4}$ 
Therefore, she is the one who has to find a solution to "her problems". Consequently, she is frequently the partner seen in the fertility clinic. Reports have shown that male factors alone account for $30 \%-40 \%$ of infertility in couples and are a contributing factor in $50 \%$ of cases. ${ }^{5}$ In a US study, $30 \%$ of fertility problems in 1000 couples were attributed to male factors. ${ }^{6}$ A similar study in Bangladesh showed male factors to be responsible for $29 \%$ of problems. $^{7}$

Another study carried out in Singapore demonstrated that $23 \%$ of infertility was due to male factors. ${ }^{8}$ In Africa, male factors account for $25 \%-37 \%$ of infertility. Reports from various centers in Nigeria ${ }^{9}$ show that male infertility accounts for $20 \%-30 \%$ of cases, which is consistent with the findings of similar studies from other regions of Africa and throughout the world. The sociocultural implications of infertility are grave, because childlessness is a major personal tragedy and a limitation for the individual concerned in this part of the world. It is an established cause of serious emotional disturbance, social and psychological pain for couples, especially the woman, and also a common cause of divorce. ${ }^{10,11}$ In our country, it is associated with self-pity, guilt, anxiety, misery, and feeling of worthlessness, unwholesomeness, and at its extreme, suicide. ${ }^{12}$

Scientifically, causes of male infertility abound and may include genetically induced causes, such as Klinefelter's syndrome, or anatomic abnormalities, such as cryptorchidism, hypospadias, varicoceles, and hormonal influences. ${ }^{3}$ Others may include drug-induced oligospermia, trauma, ionizing radiation, and severe systemic illness.

Infertility due to endocrine dysfunction was previously thought to be uncommon in African men, but with the introduction of immunoassays and other advanced technologies in urological practice in Africa, this problem has been found to constitute an important cause of infertility in African men., ${ }^{2,4}$ The causes of male infertility are many, and approximately $40 \%$ of couples may have multiple causes for their infertility. ${ }^{2,13}$ Recent advances in endocrinology have revealed that the hypothalamo-hypopyseal-testicular axis is essential for smooth endocrine function, dysregulation of which may lead to poor spermatogenesis and/or erectile dysfunction. Abnormally high or low levels of gonadotrophin, sex hormones, or cortisone-like hormones can cause infertility. The primary objective of this study was to investigate the prevalence of hormonal abnormalities in males diagnosed as infertile.

\section{Materials and methods}

This was a study of 216 men diagnosed clinically as having primary or secondary infertility and referred from the gynecology and urology units of the University of Nigeria Teaching Hospital, Enugu State University of Science and Technology Teaching Hospital, and private hospitals in and around Enugu metropolis. They were grouped into primary and secondary infertility in accordance with the World Health Organization definition. They were investigated using a routine fertility test profile for a period of 5 years from October 2004 to September 2009. Those who were on male hormone therapy or bromocriptine were excluded.

Follicle-stimulating hormone, luteinizing hormone, prolactin, testosterone, and estradiol levels were measured in each clinical group using a microwell enzyme-linked immunosorbent assay test kit for quantitative determination of hormone concentrations. Senior research fellows and/or senior resident doctors from the Department of Medical Biochemistry and Department of Chemical Pathology conducted the hormone analysis. The absorbance values for each test were used to determine the corresponding concentrations of each hormone from the standard curve developed using the kit standards. Internal control levels 1 and 2 were run with each calibration curve as the quality control instrument. The profile tests in the two clinical groups were reported hormonally as hypergonadotrophic hypogonadism, hypogonadotrophic hypogonadism, or hyperprolactinemia.

In hypertrophic hypogonadism there are usually changes in follicle-stimulating hormone, luteinizing hormone, prolactin, and testosterone levels. There may or may not be changes in estradiol levels. For hypogonadotrophic hypogonadism, the abnormal findings are in follicle-stimulating hormone, luteinizing hormone, and prolactin, and sometimes there are noticeable variations in testosterone and estradiol. Hyperprolactinemia is associated with an increase in prolactin. There may or may not be changes in folliclestimulating hormone, luteinizing hormone, testosterone, and estradiol.

\section{Statistical analysis}

The data obtained were subjected to statistical analysis using the Statistical Package for Social Sciences software (v 15; SPSS Inc, Chicago, IL). Comparison of continuous variables was made using Student's $t$-test, and $P<0.05$ indicated a statistically significant difference.

\section{Results}

Of the 216 cases studied, 173 (80\%) had hormonal abnormalities, comprising $62(35.3 \%)$ with primary infertility and 111 $(64.7 \%)$ with secondary infertility. The age range was 30-55 (mean $47.7 \pm 3.5$ ) years for the primary infertility group and 
33-61 (mean 47.2 \pm 6.8 ) years for the secondary infertility group (see Table 1). The hormonal pattern of infertility as shown in Table 2 indicates that 94 (54.34\%) of cases had hypergonadotrophic hypogonadism and $70(40.46 \%)$ had hypogonadotrophic hypogonadism. Only nine (5.20\%) showed a hormonal profile compatible with hyperprolactinemia. The results also show hormonal derangement in both groups (see Table 2). Most cases (62.90\%) of primary infertility and $49.55 \%$ of secondary infertility cases had hypergonadotrophic hypogonadism, while only 18 (29.03\%) of primary infertility cases had a hormonal picture consistent with hypogonadotrophic hypogonadism. This was in sharp contrast with the $52(46.85 \%)$ cases of secondary infertility having the same hormonal profile. There were no statistically significant differences in mean hormonal parameter values between the various hormonal diagnoses in the two groups, except for luteinizing hormone $(P=0.01)$ in those with hypergonadotrophic hypogonadism, testosterone in hypergonadotrophic hypogonadism $(P=0.04)$ and hypogonadotrophic hypogonadism $(P=0.03)$, and prolactin $(P=0.03)$ and estradiol $(P=0.03)$ in those with hypogonadotrophic hypogonadism (see Table 3 ).

\section{Discussion}

Male infertility is involved in a sexually paired couple's inability to conceive in a significant number of cases, with estimates in the range of $40 \%-50 \%$. In our environment, infertility is associated with self-pity, guilt, anxiety, misery, feelings of worthlessness and unwholesomeness, and at the extreme end, suicide. ${ }^{1,2,6,7}$ Infertility is defined as the inability to achieve a pregnancy within a specified period of time, usually 1 year, despite regular and adequate unprotected sexual intercourse. Five to seven percent of all consultations at urology clinics in Nigeria are for male infertility, which affects $20 \%-25 \%$ of married couples.

Infertility in males is reported to be common in the age group of 35-54 years, with an incidence of $8 \%-12 \%$ in various parts of the world. ${ }^{14}$ The incidence of male infertility

Table I Mean values of age and infertility profiles

\begin{tabular}{llll}
\hline Variables & $\begin{array}{l}\text { Primary } \\
\text { infertility }\end{array}$ & $\begin{array}{l}\text { Secondary } \\
\text { infertility }\end{array}$ & P value \\
\hline Cases $(\mathrm{n})$ & $62(35.3 \%)$ & $\mathrm{III}(64.5 \%)$ & - \\
Age $($ years \pm SD) & $47.7 \pm 3.5$ & $47.2 \pm 6.8$ & 0.4 \\
Follicle stimulating & 19.9 & 27.8 & 0.1 \\
hormone & & & \\
Luteinizing hormone & 23.7 & 21.4 & 0.6 \\
Prolactin profile & 29.1 & 33.9 & 0.6 \\
Testosterone & 3.9 & 4.3 & 0.9 \\
Estradiol & 29.1 & 26.2 & 0.6 \\
\hline
\end{tabular}

Abbreviation: SD, standard deviation.
Table 2 Hormonal changes of infertility by group

\begin{tabular}{lllll}
\hline $\begin{array}{l}\text { Type of } \\
\text { abnormality }\end{array}$ & $\begin{array}{l}\text { Primary } \\
\text { infertility }\end{array}$ & $\begin{array}{l}\text { Secondary } \\
\text { infertility }\end{array}$ & Total & P value \\
\hline $\begin{array}{l}\text { Hypergonadotrophic } \\
\text { hypogonadism }\end{array}$ & $39(62.90 \%)$ & $55(49.55 \%)$ & $94(54.3 \%)$ & 0.4 \\
$\begin{array}{l}\text { Hypogonadotrophic } \\
\text { hypogonadism }\end{array}$ & $18(29.03 \%)$ & $52(46.85 \%)$ & $70(40.5 \%)$ & 0.1 \\
$\begin{array}{l}\text { Hyperprolactinemia } \\
\text { Total }\end{array}$ & $5(8.07 \%)$ & $4(3.60 \%)$ & $9(5.2 \%)$ & 0.6 \\
Grand total & $62(100 \%)$ & $111(100 \%)$ & $173(100 \%)$ & \\
\hline
\end{tabular}

was reported in one study ${ }^{1,15}$ to be $20 \%-30 \%$ from various centers in Nigeria. ${ }^{10}$ The majority of cases $(78.3 \%)$ were reported to be due to secondary infertility. This study agrees with our finding of an incidence of $64.20 \%$ at an age of $47.7 \pm 3.5$ years for primary infertility and $47.2 \pm 6.8$ years for secondary infertility. This observation is also consistent with another finding of a pregnancy rate at age 38-45 years twice that at age $48-54$ years, and a probability of pregnancy at age 45 years of $67 \%$.

However, the mean age of primary infertility in this study may not be consistent with the African culture of early marriages, whereby one would expect problems with childbearing to be identified very early on in marriage. However, many studies have shown that this could be due to late presentation at hospital after alternatives have been explored. Again, the tendency of Nigerian males to embrace Western education in the recent past has markedly increased the male age of marriage to $40 \pm 5$ years. This is in contrast with the precolonial and early colonial periods when men married before the age of 25 years.

Our findings show that there is a preponderance of secondary infertility in a ratio of 2:1 compared with primary infertility. This may be attributable to a high incidence of urogenital tract infections which may be contracted through intercourse before and during marriage. This is consistent with findings in Sub-Saharan Africa, as well as reports from Latin America, where secondary infertility is more common. ${ }^{16,17}$

Male factors have been shown in several studies to be responsible for more than half of the causes of infertility in Nigeria. ${ }^{1,15}$ Because hormonal factors appear to be a major contributor to male infertility worldwide, and in this particular study, it is important that the hormonal assay be among the first-line investigations in cases of male infertility.

In over $25 \%$ of cases of infertility, more than one factor may be responsible for the childlessness, while the etiology of infertility is idiopathic in $4 \%$ of cases. The commonest cause of infertility among men in this situation is anxiety. ${ }^{3}$ 
Table $3 P$ values of hormonal pattern in primary and secondary infertility diagnosis

\begin{tabular}{lllllll}
\hline Diagnosis & Age & FSH & LH & Prolactin & Testosterone & Estradiol \\
\hline $\begin{array}{l}\text { Hypergonadotrophic } \\
\text { hypogonadism }\end{array}$ & 0.45 & 0.06 & 0.01 & 0.40 & 0.04 & 0.50 \\
$\begin{array}{l}\text { Hypogonadotrophic } \\
\text { hypogonadism }\end{array}$ & 0.71 & 0.58 & 0.39 & 0.03 & 0.03 & 0.03 \\
\begin{tabular}{l} 
Hyperprolactinemia \\
\hline
\end{tabular} & 0.06 & 0.60 & 0.60 & 0.06 & 0.06 & 0.60 \\
\hline
\end{tabular}

Abbreviations: $\mathrm{FSH}$, follicle-stimulating hormone; $\mathrm{LH}$, luteinizing hormone.

Other causes include ignorance, azoospermia, severe oligospermia, erectile dysfunction, and varicoceles. ${ }^{1,3,7}$ Vas deferens and epididymal factors may also be significant etiologic factors in Nigeria as in other third world countries due to a high incidence of chronic urinary tract infections.

In combined data from over 5000 infertile couples, $30 \%$ of problems were related to ovulation and $22 \%$ to seminal defects. Hormonal factors potentially contribute in about $50 \%$ of couples investigated. ${ }^{18}$ Ovulatory disorders, hormonal disorders, endometriosis, and genital tuberculosis have been shown to be common causes of infertility in Nigeria. ${ }^{19}$

The hormonal pattern of hypogonadotrophic hypogonadism is characterized by underproduction of follicle-stimulating hormone and luteinizing hormone, which prevents the development of functional testes, and testosterone production is severely impaired. Loss of libido and erectile dysfunction are common complications resulting from the condition. Other causes of hormonal dysfunction that could be responsible for $27.3 \%$ of cases of primary infertility are functional hypothalamic disorders as a result of anxiety and hypertension. This is usually due to disturbances in the thyroid gland and hypothalamo-hypopyseal-adrenal system.

Eating disorders, such as anorexia, bulimia, and excessive alcohol consumption (many males who are childless tend to find solace in alcohol), are often associated with infertility. Very rarely, the cause of hypogonadotrophic hypogonadism in primary infertility is pituitary infantilism, which is characterized by delayed secondary male sexual characteristics and a micropenis, and low or absent serum levels of folliclestimulating hormone and testosterone. In most cases, the cause of hypergonadotrophic hypogonadism is idiopathic. Unfortunately, this abnormal hormonal pattern accounts for infertility in more than half of cases, as well as being the commonest pattern observed in both primary and secondary infertility. This was observed to be commoner $(62.90 \%)$ in primary infertility. Hypergonadotrophic hypogonadism is characterized by high serum follicle-stimulating hormone and luteinizing hormone levels, with a corresponding low level of sex hormone (testosterone) and severe asthenoligospermia.
Production of gonadotrophin-releasing hormone in hyperprolactinemia is markedly impaired, thus inhibiting steroidogenesis. This will affect thyroid, adrenal, and testicular steroids, including testosterone production and spermatogenesis. Hyperprolactinemia was seen in $5.2 \%$ of our patients. Our study also demonstrated that hyperprolactinemia is more likely in primary infertility, although the difference was not significant when compared with secondary infertility, with many $(88 \%)$ of the primary and secondary infertility cases presented with clinically distressing gynecomastia, hypovolemic testes, and reduced libido, in contrast with men having secondary infertility who are more likely to appear physically unchanged and most of the time retain their normal libido. The mechanisms by which hyperprolactinemia may lead to seminal disorders has been highlighted by several investigators. ${ }^{18-23}$ It is important to mention that these studies showed that increased prolactin may render the testes less responsive to the effects of gonadotrophin when given exogenously to induce spermatogenesis.

It is important to mention that, in addition to hormonal derangement, there are other factors that can cause infertility. These factors include overweight, excessive exercise, hormone-disrupting chemicals, drugs, stress, chronic endocrine illnesses, and metabolic syndrome, with an incidence of $25.30 \%$. Excessive exercise, heavy smoking, weight gain, and chronic illness have been established to be more associated with secondary than primary infertility.

Unpublished studies have shown that the cost of investigation of male infertility is quite high and easily not accessible to the average Nigerian. The recently determined minimum wage in Nigeria is 18,000 Naira (US\$116) per month compared with the previous minimum wage of 7500 Naira (US\$48.40). The cost of hormone profiling alone in the public health institutions is about 35,000 Naira (US\$226) which may explain why some of these patients were lost to follow-up. It is important that government and nongovernmental organizations assist in the proper management of male infertility in Nigeria and Africa. 


\section{Conclusion}

In conclusion, a hormonal profile should be done in all cases of male infertility and should serve as a gold standard in the diagnosis of this disorder. Hormonal manipulation is a potentially successful strategy in the management of infertility.

\section{Disclosure}

The authors report no conflicts of interest in this work.

\section{References}

1. CooperTG, Noonan E, von Eckardstein, et al. World Health Organization reference values for human semen characteristics. Hum Reprod Update. 2010;16:231-245.

2. Mati JKG. The pattern of infertility in Kenya. Presented at the third European Congress of Sterility. Athens, Greece, October 1-4, 1972.

3. Ozoemena F, Ayogu B. Male infertility in Enugu and environs: A ten year prospective study. ARD_MED (Journal of Medicine). 2010;2:13-20.

4. Okonofua FE, Harris D, Odebiyi A, Thomas K, Snow RC. The social meaning of infertility in Southwest Nigeria. Health Transit Rev. 1997;7: 205-220.

5. Sciarra J. Infertility: An international health problem. Int J Gynaecol Obstet. 1994;46:155-163.

6. Turek PJ. Male infertility. In: Smith's General Urology. 16th ed. New York: Lange Book Publishers; 2004.

7. Taymor ML. Infertility. New York: Grune and Stratton; 1978.

8. Chowdhury TA, Khanam ST, Akhter M, Habib F. Profile of 350 couples attending the infertility clinic at PG Hospital in Bangladesh fertility research programme. Dacca, Bangladesh. Fifth Contributors conference, 1981.

9. Ratnam SS, Chew PCT, Tsakok M. Experience of a comprehensive infertility clinic in the Department of Obstetrics and Gynecology. Singapore Med J. 1976;17:157-159.
10. Ajabo LN, Ezimokhai M, Kediri A. Male contribution to subfertility in Benin City, Nigeria, Trop J Obstet Gynecol. 1981;2:23-56.

11. Ladipo OA. Evaluation of 576 hysterosalpingograms on infertile women. Infertility. 1979;2:63-79.

12. Akande EO. Problems of infertility in Sub Saharan Africa. Dokita. 1987; 16:23-27.

13. Okonofua FE. The case against new reproductive technologies in developing countries. Br J Obstet Gynaecol. 1996;103:957-962.

14. Cates W, Farley TM, Rowe PJ. Worldwide patterns of infertility: Is Africa different? Lancet. 1985;2:596-598.

15. Olatunji AO, Sule-Odu AO. The pattern of infertility cases at a university hospital. West Afr Med J. 2003;3:205-207.

16. Erickson K, Brunette T. Pattern and predictors of infertility among African women: A cross sectional survey of twenty-seven nations. Soc Sci Med. 1996;2:209-220.

17. Stewart-Smith GW, Iddekinge B. Lessons learned from infertility investigation in the public sector. S Afr Med J. 2003;93:141-143.

18. Williams C, Giannopoulos T, Sherriff EA. ACP best practice no 170. Investigation of infertility with the emphasis on laboratory testing and with reference to radiological imaging. J Clin Pathol. 2003;56:261-267.

19. Emokpae MA, Uadia PO, Mohammed AZ. Hormonal evaluation and endometrial biopsy in infertile women in Kano, Northern Nigeria: A comparative study. Ann Afr Med. 2005;4:99-103.

20. Austin CR, Short RV, editors. Reproduction in Mammals Series Books 1-5. Cambridge, UK: Cambridge University Press; 1992.

21. Means AR. Biochemical effects of follicle stimulating hormones on the testis. In: Greep RO, Astwood EB, editors. Handbook of Physiology. Baltimore, MD: Williams and Wilkins; 1975.

22. Mainwaring WI, Mangan FR, Wilce PA, Milroy EG. Androgens. I. A review of current research on the binding and mechanism of action of androgenic steroids, notably 5-alpha dihydrotestosterone. Adv Exp Med Biol. 1973;36:197-231.

23. Donovan BT. The role of the hypothalamus in puberty. Prog Brain Res. 1974;41:239-253.
Open Access Journal of Urology

\section{Publish your work in this journal}

The Open Access Journal of Urology is an international, peer-reviewed, open access journal publishing original research, reports, editorials, reviews and commentaries on all aspects of adult and pediatric urology in the clinic and laboratory including the following topics: Pathology, pathophysiology of urological disease; Investigation and treatment of

\section{Dovepress}

urological disease; Pharmacology of drugs used for the treatment of urological disease. The manuscript management system is completely online and includes a very quick and fair peer-review system, which is all easy to use. Visit http://www.dovepress.com/testimonials.php to read real quotes from published authors. 